\title{
Bilateral Intracranial Subdural Haematoma Occurring after Spinal Anaesthesia: A Case Report
}

\author{
Spinal Anestezi Sonrası Gelişen Bilateral Intrakranial Subdural Hematom: \\ Olgu Sunumu
}

Abdulkadir İskender', Ömer Aykanat' ${ }^{2}$, Hayati Kandiş3

'Department of Anaesthesiology and Reanimation, Faculty of Medicine, Düzce University, Düzce, Turkey 2Department of Brain and Neurosurgery, Faculty of Medicine, Düzce University, Düzce, Turkey ${ }^{3}$ Department of Emergency Medicine, Faculty of Medicine, Düzce University, Düzce, Turkey

\section{ABSTRACT}

Intracranial subdural haematoma occurring after spinal anaesthesia is very uncommon but is a serious complication that can be fatal if treatment is not administered. Cerebrospinal fluid (CSF) leakage originating from a dural puncture may cause haemorrage by dehiscence of the meningeal vessels. In this article, a case of a subdural haematoma following spinal anaesthesia is presented. Subdural bleeding should be considered in cases of a headache occurring after spinal anaesthesia.

Keywords: Anaesthesia, spinal, subdural haematoma Received: 09.11.2011 Accepted: 15.05.2013

\section{ÖZET}

Spinal anestezi sonrası gelişen intrakranyal subdural hematom, seyrek rastlanan ve gerekli tedavisi yapılmadığı takdirde öldürücü olabilen ciddi bir komplikasyondur. Ponksiyon sonrası gelişen dural zedelenme nedeniyle meydana gelen beyin omurilik SIVISI (BOS) sızıntısı, meningiyal damarlarda yırtılmaya ve böylece kanamaya yol açmaktadır. Bu yazıda spinal anestezi sonrası bilateral intrakranial subdural hematom gelişen bir vaka sunulmaktadır. Spinal anestezi yapılan vakalarda medikal tedaviye rağmen devam eden baş ağrısında subdural hematom akılda tutulmalıdır.

Anahtar Kelimeler: Anestezi, spinal, subdural hematom Geliş Tarihi: 09.11.2011 Kabul Tarihi: 15.05.2013

\section{Giriş}

Subdural hematomlar genellikle dural sinüsler ve korteks arasındaki venlerin yırtılması veya direkt dural sinüslerin zedelenmesi sonucu oluşur (1). Subdural hematomların etyolojisinde en sık travma yer alır. Serebral atrofi, antikoagülan kullanımı, yaş ise predispozan faktörlerdir. Spinal anestezi sonrası gelişen intrakranial subdural hematom ise nadir görülen fakat iyi tanımlanmış bir durumdur (2). Ancak bilateral intrakranial subdural hematoma ait literatürde çok az sayıda yayın bulunmaktadır (3). Spinal anestezinin en yaygın komplikasyonu baş ağıııdır. Dura zedelenmesi sonucu ortaya çıkan baş ağrısı genellikle postural olup, sıvı alımı ve yatak istirahati ile yaklaşık olarak 2 günde geçmektedir. Ancak baş ağrısı uzun süre devam ediyorsa akla subdural hematom (SDH) gibi intrakranyal hadiseler gelmelidir (4). Bu olgu sunumunda spinal anestezinin nadir bir komplikasyonu olan bilateral intrakranial subdural hematomlu bir vakayı sunduk.

\section{Olgu Sunumu}

Yirmi sekiz yaşında bayan hasta acil servise şiddetli baş ağrısı ve bulantı-kusma şikayetleri ile başvurdu. Hastadan onam alınmıştır. Hastanın öz geçmişinden 1 hafta önce spinal anestezi ile doğum yaptığı ve doğum sonrası baş ağrısı, bulantı şikayetinin başladığı, gün geçtikçe şikayetlerinin arttığı öğrenildi. Hasta kendi hekimine başvurduğunu, kendisine istirahat, analjezik ve bol sıvı alması önerildiğini ancak tüm bu tedavilere rağmen baş ağıısının geçmediğini belirtti. Hastanın yapılan muayenesinde GKS14 (E3M6V5), şuuru uykuya meyilli, ajite, koopere ve oryanteydi. Hastada lateralizan bulgu tespit edilmedi. Öyküsünde travma, koagülopati ve anti-koagülan ilaç kullanımı olmayan hastaya çekilen kranial MRG'de bilateral frontotemporoparietal bölgede sıvama tarzında subdural hematom tespit edildi (Resim 1-3). Beyin ve Sinir Cerrahisi tarafından konsülte edilen hasta gerekli 


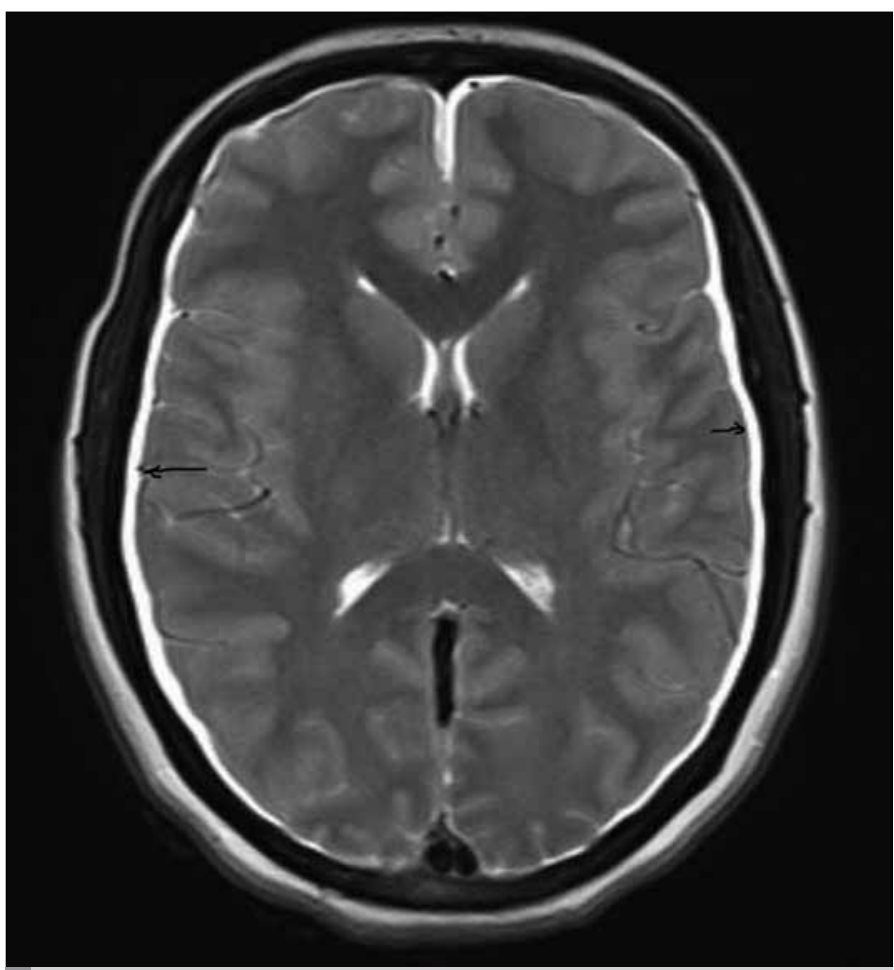

Resim 1.T2 sekanslı, aksiyel kesitli kranial MRG'de bilateral frontotemporoparietal bölgede sıvama tarzında subdural hematom

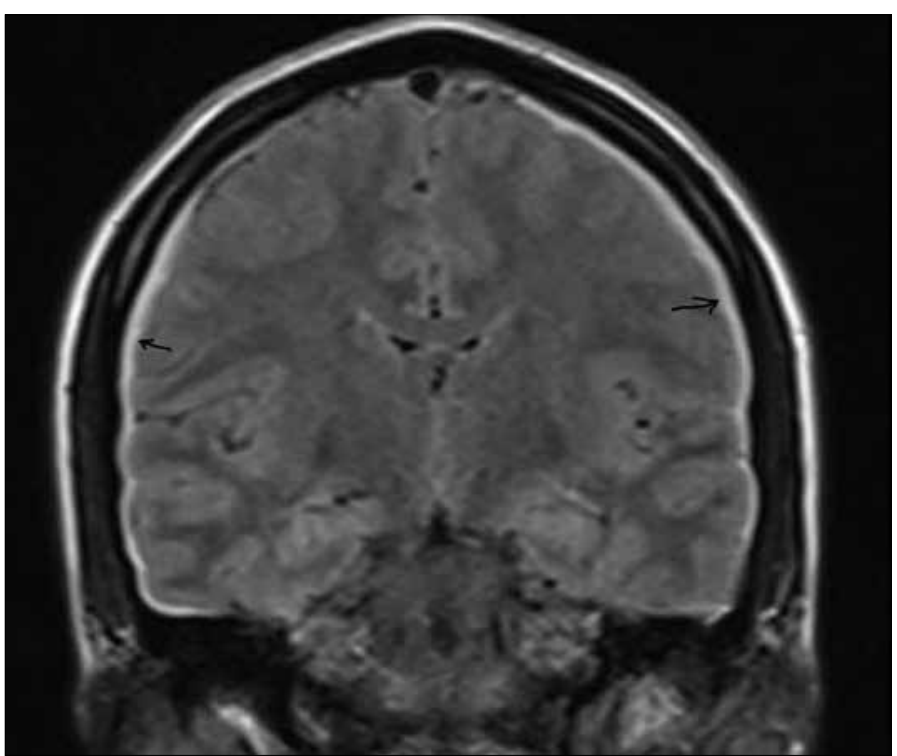

Resim 2. T1 sekanslı, koronal kesitli kranial MRG'de bilateral, hiperintens subdural hematom

medikal tedavisi planlanarak beyin cerrahisi servisine yatırıldı. Hastaya yattığı müddetçe analjezik, antienflamatuar tedavi dışında ek bir tedavi verilmedi. Takiplerinde gün geçtikçe şikayetlerinin gerilediğini belirten hasta yatışının 5. gününde şifa ile taburcu edildi.

\section{Tartışma}

Spinal anestezi sonrası gelişen intrakranial subdural hematomun en sık rastlanan semptomu baş ağrısı olmakla birlikte kusma, görme

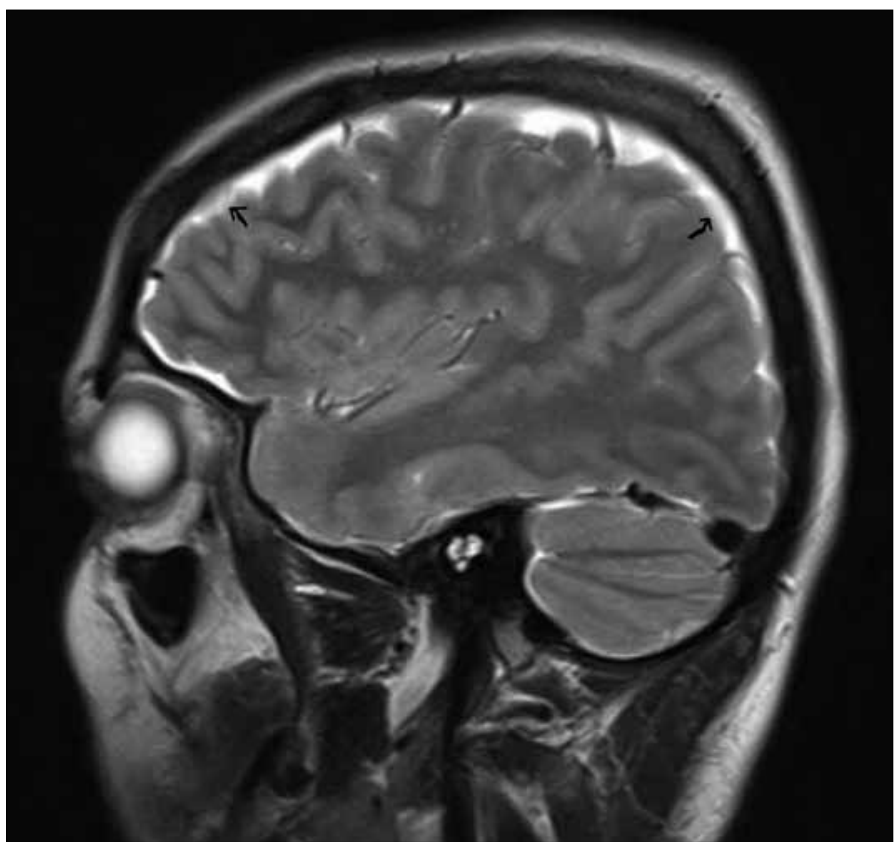

Resim 3. Aynı hastanın sagittal kesitli kranial MRG görünümü

kaybı, epileptik nöbetler, kulak çınlaması ve işitme kaybı gibi semptomlar da görülebilmektedir $(4,5)$. Spinal anestezi sonrası gelişen baş ağrısı girişimden sonraki ilk 2 hafta içerisinde başlayabilir. Ancak olguların yaklaşık \%90'ında ilk 3 günde başladığı bildirilmiştir (6). Baş ağrısının nedeni olarak dural zedelenme sonucu günde $250 \mathrm{~mL}$ BOS kaçağı olması ve bunun da BOS basıncının düşmesine neden olması gösterilmektedir (7). Dura ponksiyonu sonrası gelişen baş ağrısı ile subdural hematomun neden olduğu baş ağrısını ayırmak zor gibi görünse de iyi bir anamnez, fizik ve nörolojik muayene ile rahatça intrakranial bir hadiseden şüphelenip gerekli radyolojik yöntemle tanı konulabilmektedir. Baş ağrısının 5 günden uzun sürmesi, istirahat ve medikal tedaviye rağmen devam etmesi subdural hematomu destekleyen bulgular arasındadır $(8,9)$. Koagülasyon bozukluğu, kadın cinsiyet, ileri yaş, atrofik beyin, beyin tümörü ve serebrovasküler hastalıkların varlığı subdural hematomun görülme sıklığını artırmaktadır (7). Bizim vakamızda hastanın kadın olması dışında herhangi bir risk faktörü tespit edilmemiştir. Spinal anestezi sonrası gelişen subdural hematomun tedavi şeması bellidir. Kalınlığı 5 mm'nin üstünde olan hematomlarda ve ilerleyici nörolojik defisiti olan hastalarda cerrahi tedavi önerilirken, 5 mm'nin altında olan hematomlar sıklıkla spontan olarak rezorbe olduğu için bu hastalara konservatif tedavi yeterli görülmektedir (10). Baş ağrısı içinse erken yapılan epidural kan yamasının en etkili tedavi yöntemi olduğu bilinmekle birlikte istirahat, kafein ve analjezik tedavisi de mutlaka önerilmelidir $(5,8)$.

\section{Sonuç}

Spinal anestezi sonrası dirençli ve uzamış baş ağıısında intrakranial hematomun olabileceği akılda tutulmalıdır. Acil servise başvurması muhtemel olan bu hastalara gerekli radyolojik yöntemlerle erken tanı konması hasta ve hekim için hayati önem arz etmektedir.

\section{Conflict of Interest}

No conflict of interest was declared by the authors. 
Peer-review: Externally peer-reviewed.

\section{Author Contributions}

Concept - A.I.I, Ö.A; Design - A.I.; Supervision - A.I.., H.K.; Funding - A.I.l; Materials - A.I.; Data Collection and/or Processing - A.I., Ö.A., H.K.; Analysis and/or Interpretation - Ö.A.; Literature Review - A.I., Ö.A., H.K.; Writer - A.I., Ö.A.; Critical Review - A.I., H.K.

\section{Çıkar Çatışması}

Yazarlar herhangi bir çıkar çatışması bildirmemişlerdir.

Hakem değerlendirmesi: Dış bağımsız.

\section{Yazar Katkıları}

Fikir - A.I., Ö.A; Tasarım - A.I.; Denetleme - A.I.I, H.K.; Kaynaklar - A.I.; Malzemeler - A.l.; Veri toplanması ve/veya işlemesi - A.I., Ö.A., H.K.; Analiz ve/veya yorum - Ö.A.; Literatür taraması - A.I.., Ö.A., H.K.; Yazıyı yazan - A.I., Ö.A.; Eleştirel İnceleme - A.I., H.K.

\section{Kaynaklar}

1. Azzarelli B. Neuropathology of the central nervous system: Trauma, Cerebrovascular Disease, Infections, Demyelinating, Neurodegenerative, Nutritional and Metabolic Disorders. H.Hunt Batjer - Christopher M.
Loftus (ed), Textbook of neurological surgery, cilt 1, Philadelphia: Lippincott Williams \& Wilkins, 2003: 207-33.

2. Pavlin DJ, McDonald JS, Child B. Acute subdural hematoma: an unusual sequela to lumbar puncture. Anesthesiology 1979; 51:338-40. [CrossRef]

3. Slowinski J, Szydlik W, Sanetra A, Kaminska I, Mrowka R. Bilateral chronic subdural hematomas with neurologic symptoms complicating spinal anesthesia. Reg Anesth Pain Med 2003; 28: 347-50. [CrossRef]

4. Kelsaka E, Sarihasan B, Baris S, Tur A. Subdural hematoma as a late complication of spinal anesthesia. J Neurosurg Anesthesiol 2003; 15: 47-9. [CrossRef]

5. Yıldırım B, Çolakoğlu S, Atakan TY, Büyükkirli H. Intracranial subdural hematoma after spinal anesthesia. Int J Obstet Anesth 2005; 14: 159-62. [CrossRef]

6. Turnbull DK, Shepherd DB. Post-dural puncture headache: pathogenesis, prevention and treatment. Br J Anaesth 2003; 91: 718-29. [CrossRef]

7. Işık B, Yiğit N, Kordan AZ, Kardeş Ö, Özköse Z. Postspinal bilateral intrakranyal subdural hematom (olgu sunumu) Marmara Medical Journal 2005; 18: 135-9.

8. Saha D, Saika S, Bhattacharya D, Joseph T, Mukherjee P: Chronic subdural hematoma following spinal anesthesia a case report. Indian J Anesth 2004; $13: 312-48$

9. Suess O, Stendel R, Baur S, A. Schilling, M. Brock: Intracranial hemorrhage following lumbar myelography. Case report and rewiev of the literature. Neuroradiology 2000; 14: 211-42. [CrossRef]

10. Vaughan DJ, Stirrup CA, Robinson PN. Cranial subdural haematoma associated with dural puncture in labour. Br J Anaesth 2000; 20: 518-84. [CrossRef] 